\title{
Performance and Emission Characteristics of Pongomia Oil using VCR Engine with Turbo Charger Setup
}

\author{
S.Prakash, M.Prabhahar, Rajkumar, Saran Kumar.S, Prasanth. S
}

\begin{abstract}
The diesel motors has prompted the outflow of risky gases like Sulfur oxides, nitrogen oxides and carbon monoxide, which can additionally prompted issues like acid rain, These discharges can likewise influence human well being and increment a dangerous atmospheric devation which has prompted the requirement for interchange energizes. Biodiesel is one of the choices which are by and large broadly considered and its generation from oil seeds is constrained by yield land dislodging, The impact of variable pressure proportion at various burdens with turbocharger is utilized to break down the presentation and to improve the exhibition of an I.C motor and to expand the effectiveness of the single chamber four stroke diesel motors. The turbocharger is utilizations to the vitality of fumes gas to drive more air-fuel blend into chamber to expand the motor power. The properties of Pongamia pinnata oil mixes with diesel are tried in a variable pressure proportion motor (VCR motor) with turbo charger arrangement. The presentation attributes of the motor are utilized to decide the brake control, explicit fuel utilization, warm effectiveness, and so on.
\end{abstract}

Keywords: Pongamia pinnata oil, VCR Engine, Turbo Charger

\section{INTRODUCTION}

The diesel motors has prompted the emanation of perilous gases like Sulfur oxides, nitrogen oxides and carbon monoxide, which can additionally prompted issues like corrosive downpour, These discharges can likewise influence human wellbeing and increment an Earth-wide temperature boost which has prompted the requirement for substitute powers. Biodiesel is one of the options which are in effect broadly contemplated and its generation from oil seeds is constrained by harvest land relocation, The impact of variable pressure proportion at various burdens with turbocharger is utilized to break down the exhibition and to improve the presentation of an I.C motor and to build the productivity of the single chamber four stroke diesel motors. The turbocharger is utilizations to the vitality of fumes gas to drive more air-fuel blend into chamber to expand the motor power. The properties of Pongamia pinnata oil mixes with diesel are tried in a variable pressure proportion motor (VCR motor) with turbo charger arrangement. The presentation qualities of

Revised Manuscript Received on September 22, 2019

* Correspondence Author

S.Prakash -Research Scholar, Department of Mechanical Engineering, Aarupadai Veedu Institute of Technology, Vinayaka Mission Research Foundation, Deemed to be University Prakash.mech94@gmail.com

Dr. M.Prabhahar - Professor, Department of Mechanical Engineering, Aarupadai Veedu Institute of Technology, Vinayaka Mission Research Foundation, Deemed to be University mprabhahar@gmail.com

Rajkumar, Saran Kumar. S,Prasanth. S, UG Scholar, Aarupadai Veedu Institute of Technology, Vinayaka Mission'S Research Foundation the motor are utilized to decide the brake control, explicit fuel utilization, warm proficiency, and so forth. Because of weight on palatable oils like groundnut, rapeseed, mustard and soybean and so forth non-eatable oil of jatropha curcas and karanja (PongamiaPinnata) are assessed as diesel fuel extender. Pongamia pinnata is a types of family Leguminasae, local in tropical and calm Asia including some portion of India, China, Japan, Malaysia, Australia. Generally it is called as karanja (in MS), pongam (in Gujarat), dalkaramch (in Tamilnadu). Karanja is dry season safe, semi-deciduous, nitrogen fixing leguminous tree. It develops around 15-20 meters in tallness with a huge covering which spreads similarly wide. The leaves are delicate, sparkly burgundy in late-spring and develop to a lustrous, dark green as the season advances. [2] Flowering beginnings as a rule following 4-5 years. Editing of cases and single almond estimated seeds can happen by 4-6 years and yields 9-90 kg's of seed. The yield potential per hectare is 900 to $9000 \mathrm{Kg} / \mathrm{Hectare}$. According to statics accessible pongamia oil has a capability of 135000 million tones for every annum and just $6 \%$ is being used. The tree is appropriate to serious warmth and daylight and its thick system of parallel roots and its thick long tap roots make it dry season tolerant.

\section{A. ORIGIN OF PROBLEM}

At present scenario every country is facing two major challenges namely energy crisis and environmental degradation. Carrying need of the day to mean fuel, more fuel and cheaper fuel. [1] Particulate matter (PM), oxides of nitrogen (NOX)carbon monoxide(CO),total hydrocarbon(THC) are the causes of acid rain, depletion of ozone layer and various respiratory problem.

\section{B. OBJECTIVE OF THE PAPER}

To experimentally, find the optimum running parameters of diesel engine were the emission level will be minimum and performance can be enhanced. Increase the dependency on biodiesel fuel. To save the fossil fuel for further generation and provide the hazard free environment.

\section{LITERATURE REVIEW}

Bryan R. Moser et al. Coriander (C. sativum L.)(2012) were evaluated seed oil methyl esters as an alternative biodiesel fuel and were prepared in $94 \mathrm{wt} \%$ yield by a standard transesterification procedure with

methanol and sodium methoxide catalyst. Acid-catalyzed pretreatment was necessary beforehand to reduce the AV of the oil from 2.66 to $0.47 \mathrm{mg} \mathrm{KOH} \mathrm{g-1.} \mathrm{Coriander} \mathrm{oil}$ contained a high level of petroselinic acid (68.5 wt\%) hitherto unreported as the principle FA component in 
biodiesel fuels. [7] Paula Berman et al.(2013) Investigated Alternative oilseeds are being used as biodiesel feed stocks. In this study, the specifications in ASTM D6751 and D7467 which are related to the fatty acid composition of pure castor methyl esters (B100) and its blend with petro diesel in a 10\% volume ratio (B10) were investigated. [8] M.K.-K. Figueiredo et al.(2014) a Low Temperature Conversion (LTC) process carried out on a sample of castor seeds, Ricinus communis, generated fractions of pyrolysis oil, pyrolitic char, gas and aqueous extracts in the following relative amounts, respectively: $50 \%, 28 \%, 10 \%$ and $12 \%$ $[\mathrm{w} / \mathrm{w}]$. The pyrolysis oil was added at loadings of $2 \%, 5 \%$, $10 \%, 20 \%$ and $30 \%[\mathrm{w} / \mathrm{w}$ ] to commercial diesel. The LTC of the castor seeds was carried out under a constant nitrogen flow at $380 \mathrm{oC}$, the collection of four fractions: pyrolysis oil [50\%], aqueous [12\%], pyrolitic char [28\%] and gas [10\%] fractions. Significant absorptions of pyrolysis oil in the FTIR spectra are as follows: $3349 \mathrm{~cm}-1$ (axial deformation of $-\mathrm{OH}$ group); $2924 \mathrm{~cm}-1$ and $2854 \mathrm{~cm}-1$ (axial deformation of C-C aliphatic); $1711 \mathrm{~cm}-1$ (carbonyl group) and $1463 \mathrm{~cm}-1$ (angular deformation of $-\mathrm{CH} 3$ and $-\mathrm{CH} 2-$ groups). The results of the analyses obtained where all were made using mixtures of diesel reference. The high percentage of the pyrolysis oil fraction (50\%) obtained by the LTC process from castor seeds makes this biomass a very promising energy source in admixtures with commercial diesel. The results obtained in this work show that binary mixtures ( $\mathrm{P}$-diesel) of up to $10 \%$ pyrolysis oil in commercial diesel are very effective. Horng-Wen Wu et al.(2015) determined the optimal operating factors for achieving good combustion performance, low NOx and smoke, at various engine loads and at $1500 \mathrm{rpm}$ he used taguchi method to determine the optimal combinations of concentrations for a diesel engine with diesel/biodiesel blend using $\mathrm{H} 2$ and cooled exhaust gas recirculation (EGR) at the inlet port. Furthermore, the combustion performance and emissions are compared between the optimum combination factors and original baseline diesel engine. As a result he observed that for a combination of B20 (A2), 30\% hydrogen (B3) and 40\% EGR ratio $(\mathrm{C} 3)$ the performance characteristics like brake thermal efficiency and specific fuel consumption is more which got at a load of $60 \%$, the reduction rate is $25.4 \%$ for BSFC, $74.1 \%$ for NOx and $29.6 \%$ for smoke. The predictions using Taguchi's parameter design technique are in adequate agreement with the confirmation results, with a confidence interval of $95 \%$, and this technique saves $67 \%$ of the time taken to perform the experiment in this research.

\section{EXPERIMENTAL SETUP}

Presently a day, explores were being a ton of doing work in I.C motor to improve the motor productivity. Diesel motor were utilized in gaseous petrol for financial and condition control points of interest. This venture will survey the variable pressure proportion for various burden utilizing single chamber four stroke diesel motors to decide the parameter and delivered the greatest vitality proficiency. Diesel motors described are low fuel utilization and low outflow for $\mathrm{CO}$ and NOx will be high. A significant issue in NOx outflow is higher for the contamination control. Because of contact misfortune and fumes loss of the presentation at influence the proficiency. It appears that a fuel utilization rate is lower contrast with pressure proportion is high in the part load. The motor arrangement comprises of a solitary chamber, four strokes, variable pressure proportion associated with vortex current dynamometer. A kirloskar motor is altering to variable pressure proportion diesel motor. The primary segments of the framework are fuel infusion siphon, dynamometer, turbocharger, fumes gas analyser. An important instrument is a burning pressure, wind current, temperature, wrench edge, cylinder, fuel stream and burden estimations. The rota meter is utilizations to cooling water and calorimeter water stream are estimated. The motor execution were arrangement study incorporates of torque, brake control, demonstrated power, grinding power, brake explicit fuel utilization, showed explicit fuel utilization, brake warm proficiency, demonstrated warm effectiveness and warm productivity.

\section{THEORETICAL CALCULATIONS}

[3] Compression Ratio: It is the ratio of the total volume of the combustion chamber if the piston moved at bottom dead centre to the total volume of the combustion chamber if the piston moved at top dead centre. $R c=\frac{\text { Total Volume at } B D C}{\text { Total Volume at } T D C}$. Friction Power: The link between the output of brake power and the output of indicated power of an engine. FP = IP-BP. [4] Indicated Power: It may be the power developed by combustion of fuel in the combustion chamber. It is the sum of friction power and brake power. $I P=\frac{\text { ImepLAN }}{60}$. Indicated Mean Effective Pressure: It may be the average pressure acting on a piston during a power stroke of its cycle. Imep $=\frac{60 I P}{L A N}$. Brake Specific Fuel Consumption: It may be thought of as fuel consumption per unit of thrust of the brake power. $B S F C=\frac{M}{B P}$ Indicated Specific Fuel Consumption: It may be thought of as fuel consumption per unit of thrust of the indicated power. $I S F C=\frac{M}{I P}$. [5] Brake Thermal Efficiency: It is defined as brake power of a heat engine as a function of the thermal input from the fuel. $B T E=\frac{B P * a 600}{M * C V}$. [6] Indicated Thermal Efficiency: It is defined as the ratio between the indicated power output of an engine and the rate of supply of energy in the fuel. $I T E=\frac{I P * a 600}{M * C V}$. Mechanical Efficiency: It is measured as a ratio of the measured performance of an ideal machine. $M E=\frac{B P}{I P}$

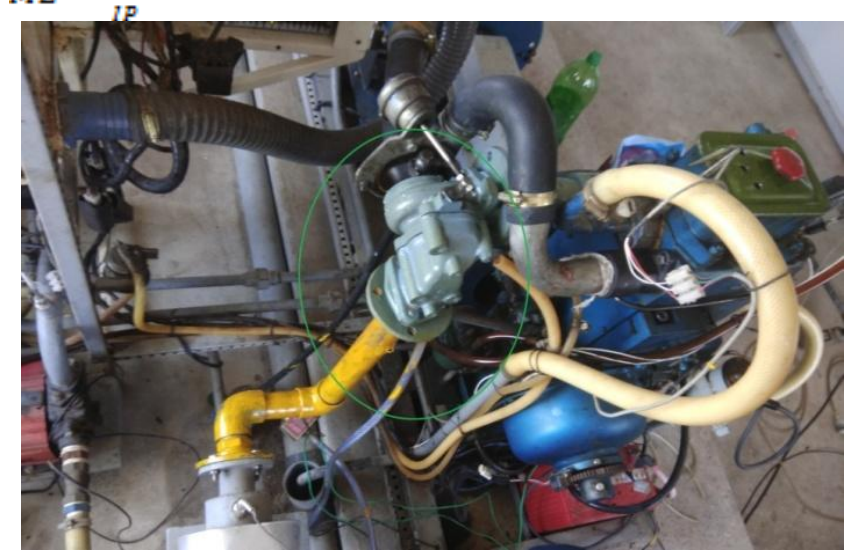




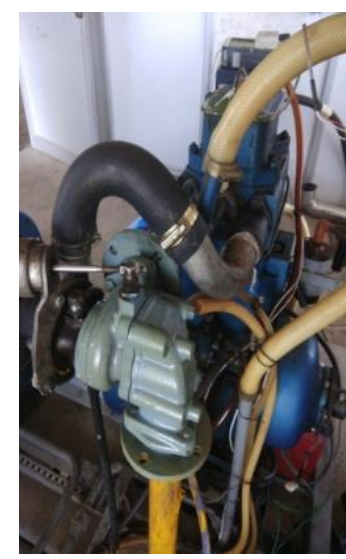

Fig 1: Engine Setup with using Turbocharger

A variable compression ratio idea has additionally been assessed by methods for the reenactment of a turbocharged diesel motor. The impact of compression ratio on the motor execution at fixed burdens will be exhibited. The chief advantages are a decrease in fuel utilization at part load and a decrease in start delay. The expansion in the admission lift weight improves the brake warm effectiveness of the motor. For the pay of drop in volumetric proficiency of the protected motor $4 \%$ admission lift weight is required for turbocharging.

\section{RESULTS AND DISCUSSION}

The experiments were conducted with diesel fuel and Pongamia Biodiesel B20,B40 and B100 under the Turbo Charger setup. The results obtained from the experimental investigations, the combustion, performance and emission parameters were measured and discussed in this section.

\section{A. BRAKE THERMAL EFFICIENCY}

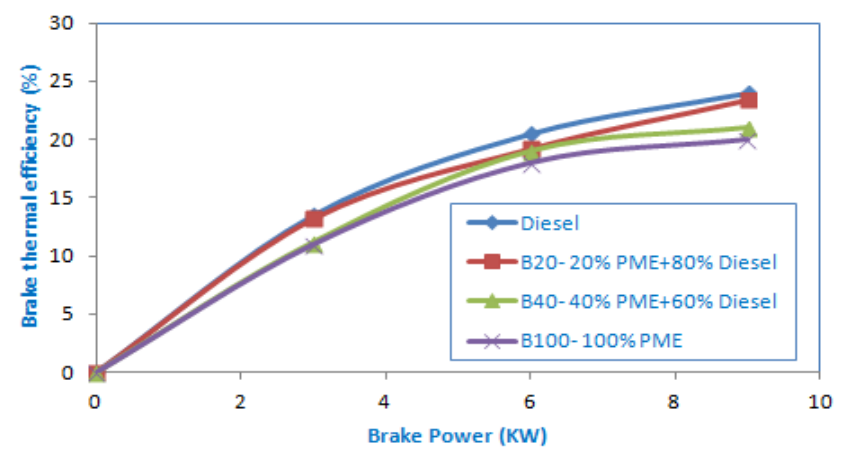

Fig 2: Variation of Brake thermal efficiency with BP

The maximum brake thermal efficiency for neat diesel is $21 \%$. For B20 it is $23.4 \%$, for B40 it is $21 \%$, for $\mathrm{B} 100$ it is $20 \%$. It can be seen that the Brake thermal efficiency characteristics for diesel is highest and lesser in the case of all biodiesel blends. This may be due to the reduced calorific value and increased viscosity of biodiesel when compared to diesel. Among the biodiesel blends, the maximum brake thermal efficiency is obtained for B20 blend (20\% BME with $80 \%$ of diesel) at three fourth of load. This may be due to the reduced viscosity and increased calorific value, which leads to better combustion when compared to other biodiesel blends.

\section{B.BASIC SPECIFIC FUEL CONSUMPTION}

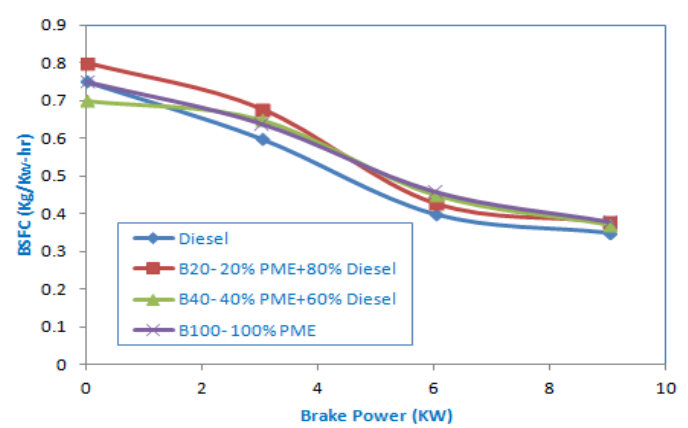

Fig 3: Variation of BSFC with BP

Specific energy consumption for neat diesel at three fourth of the load is $0.35 \mathrm{Kg} / \mathrm{KW}$-hr. For diesel blends it starts to increase by $0.36 \%, 0.37 \%, 0.37 \%$, for B20, B40 and B100 respectively. It is seen that the specific energy consumption characteristics for diesel is least and highest in the case of all biodiesel blends. This may be due to the less energy content of biodiesel when compared to diesel. Among all the biodiesel blends, B20 blend has lowest specific energy consumption at three fourth loads. This may be due to the higher energy content of the blend, which leads to better combustion when compared to other biodiesel blends.

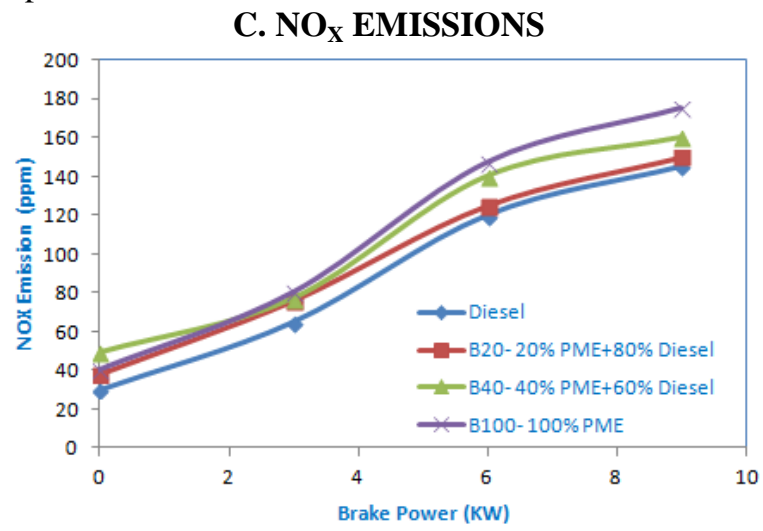

Fig 4: Variation of $\mathrm{NO}_{\mathrm{X}}$ emissions with $\mathrm{BP}$

The $\mathrm{NO}_{\mathrm{X}}$ emission for neat diesel at maximum load is 145 ppm and it starts to increase for the biodiesel blends. The emission increases by 150,160 and 175 B20, B40 and B100 for respectively. Among all the biodiesel blends, B20 has the minimum NOX emission. This may be due to the reduced viscosity and better combustion, which leads to higher combustion temperatures when compared to other biodiesel blends.

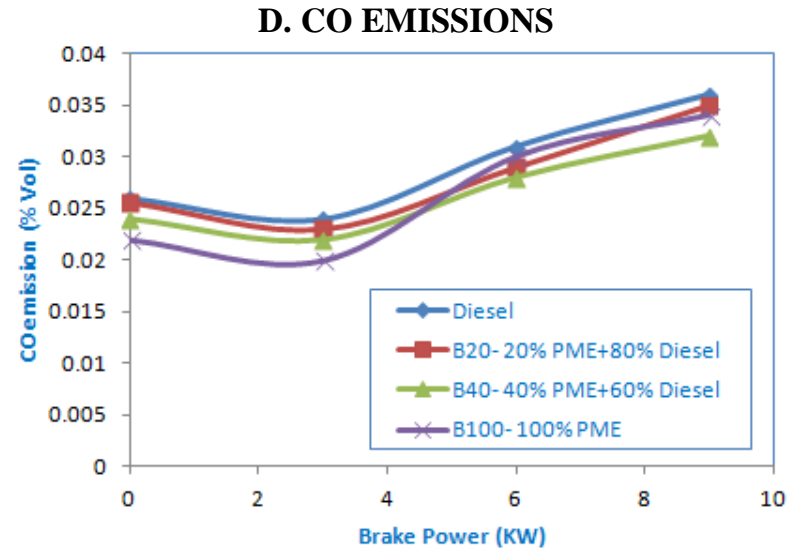

Fig 5: Variation of CO emissions with BP

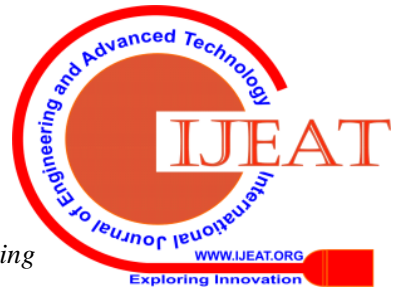


Fig 5 Shows The carbon monoxide emissions for neat diesel at maximum load are $0.036 \%$. The emissions decrease by $0.35 \%, 0.32 \%, 0.034 \%$, for $\mathrm{B} 20, \mathrm{~B} 40$, and $\mathrm{B} 100$ respectively at maximum load. Among the biodiesel blends B20 has the minimum $\mathrm{CO}$ emission. The result may be due to the lower carbon to hydrogen ratio of biodiesel when compared with diesel.

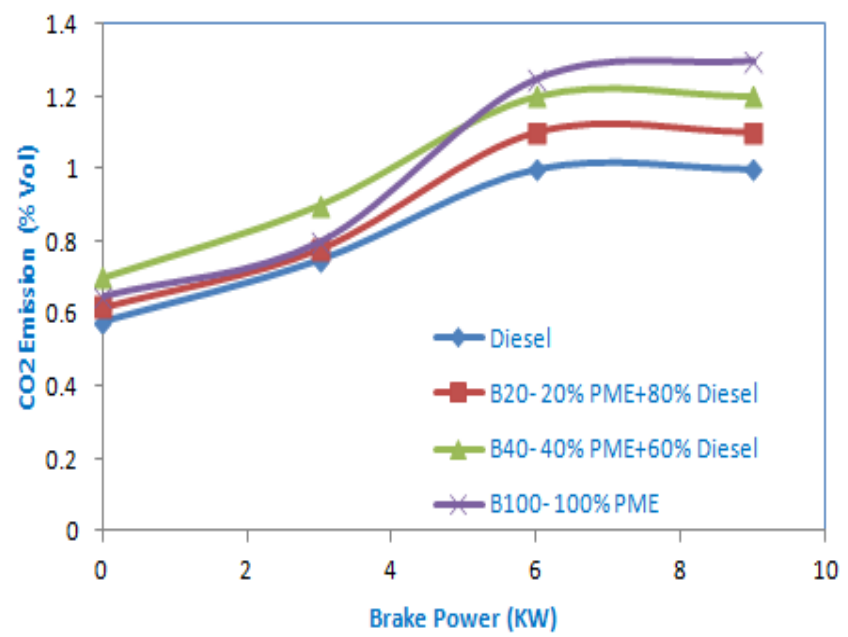

\section{E. $\mathrm{CO}_{2}$ EMISSIONS}

Fig 6 shows The co2 emission for neat diesel at maximum load is $1 \%$. And for diesel blends it is $1.1 \%, 1.2 \%$ and $1.3 \%$ for $\mathrm{B} 20, \mathrm{~B} 40$, and $\mathrm{B} 100$ respectively. When compared to other diesel blends B20 has nearest minimum co2 emission value, this is due to reduced viscosity of the blend.

\section{F. HYDRO CARBON EMISSIONS}

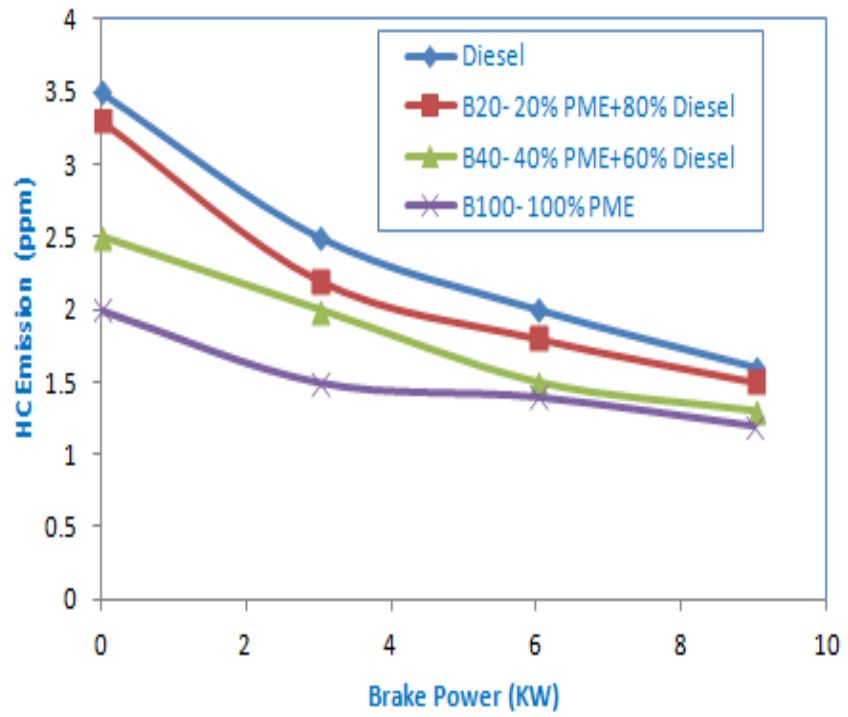

Fig 7: Variation of HCemissions with BP

The hydro carbon emission for neat diesel at maximum load is $1.6 \mathrm{ppm}$ and it starts to decrease for bio diesel blends. The emission decreases to $1.5 \mathrm{ppm}, 1.3 \mathrm{ppm}, 1.2 \mathrm{ppm}$ B20, B40, and B100 for respectively. This may be due to the fact that all the biodiesel contain oxygen in their chemical composition. This favours comparatively better combustion for biodiesel than diesel.

\section{G.O2 EMISSIONS}

Fig 6: Variation of $\mathrm{CO}_{2}$ emissions with $\mathrm{BP}$

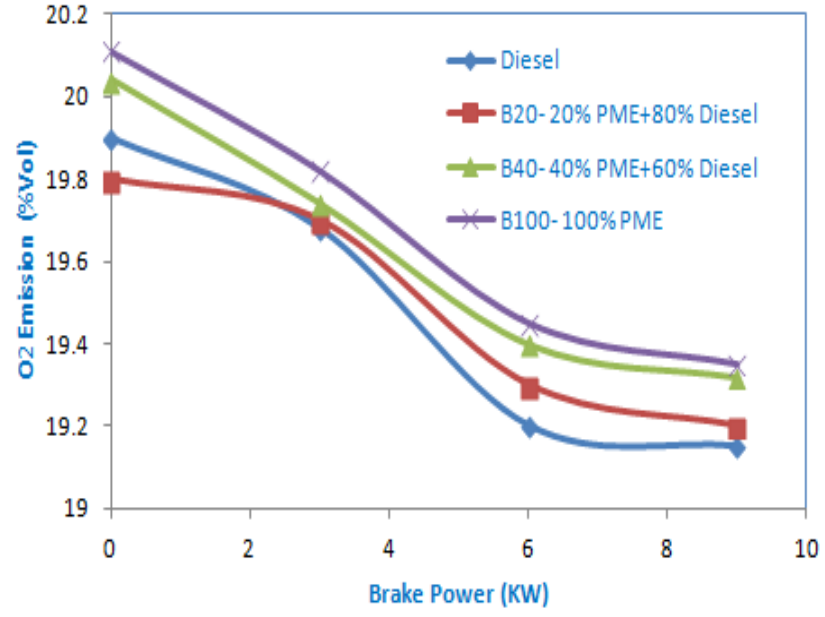

Fig 8: Variation of $\mathrm{O}_{2}$ emissions with $\mathrm{BP}$

The $\mathrm{O}_{2}$ emission for neat diesel at maximum load is $19.15 \%$ vol and it starts to Increase for bio diesel blends. The emission increase to $19.2 \% \mathrm{vol}, 19.32 \% \mathrm{vol}, 19.35 \% \mathrm{vol}$ for $\mathrm{B} 20, \mathrm{~B} 40$, and B100 for respectively. The variation is mainly due to the difference in the degree of oxygenation of the different feedstock's and its chemical composition. Highly saturated oils, when used as feedstock's for biodiesel production are more oxygenated, burns cleaner and stable.

\section{H. SMOKE DENSITY}

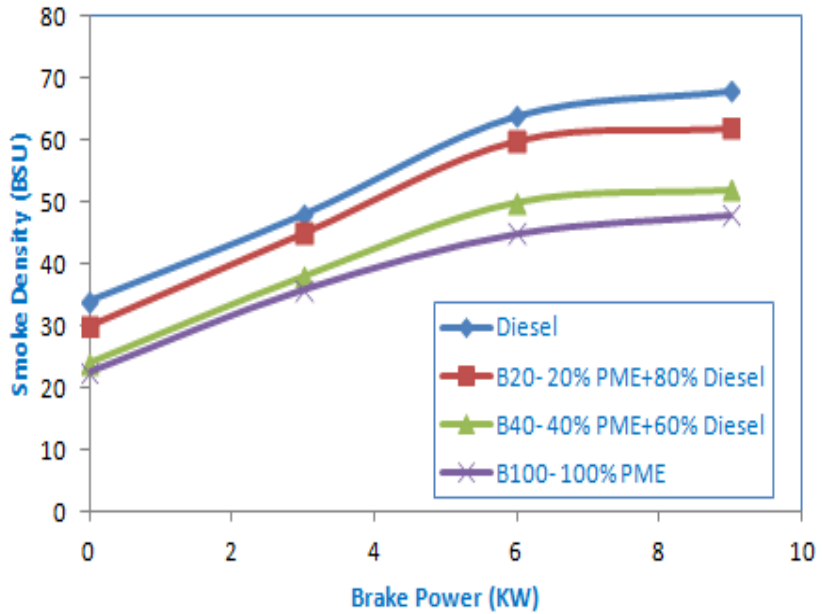

Fig 9: Variation of Smoke Density with BP

The variations of smoke density at different engine load are presented for neat diesel at maximum load is $68 \mathrm{BSU}$. The smoke emission increases with an increase in the load for all fuels. The smoke density for diesel is $3.6 \mathrm{BSU}$ at full load, whereas for B20 and B100 it is 62 BSU and 48 BSU at full load. The reduction in smoke for biodiesel blends may be due to more oxygen atom present in the biodiesel, resulting in better combustion of biodiesel.

\section{CONCLUSION}

Comparison of various performance and emission characteristics among diesel and various blends of Biodiesel with diesel 
Table 1: Various Characteristics of Biodiesel with Diesel

\begin{tabular}{|c|c|c|c|c|}
\hline $\begin{array}{c}\text { VARIOUS } \\
\text { CHARACTERISTICS }\end{array}$ & DIESEL & $B 20$ & $B 40$ & $B 100$ \\
\hline $\begin{array}{c}\text { Brake Thermal } \\
\text { Efficiency (\%) }\end{array}$ & 24 & 23.4 & 21 & 20 \\
\hline $\begin{array}{c}\text { Specific Energy } \\
\text { Consumption (Kg/Kw/Hr) }\end{array}$ & 0.35 & 0.38 & 0.37 & 0.38 \\
\hline $\begin{array}{c}\text { Nitrogen Oxide } \\
\text { Emissions (Ppm) }\end{array}$ & 145 & 150 & 160 & 175 \\
\hline $\begin{array}{c}\text { Carbon Monoxide } \\
\text { Emissions (\%Vol) }\end{array}$ & 0.036 & $\begin{array}{c}0.03 \\
5\end{array}$ & 0.032 & 0.034 \\
\hline $\begin{array}{c}\text { Carbon Dioxide } \\
\text { Emissions (\%Vol) }\end{array}$ & 1 & 1.1 & 1.2 & 1.3 \\
\hline $\begin{array}{c}\text { Hydro Carbon } \\
\text { Emissions (Ppm) }\end{array}$ & 1.6 & 1.5 & 1.3 & 1.2 \\
\hline $\begin{array}{c}\text { Oxygen (\%Vol) } \\
\text { Smoke Density (Bsu) }\end{array}$ & 19.15 & 19.2 & 19.32 & 19.35 \\
\hline Among & 68 & 62 & 52 & 48 \\
\hline
\end{tabular}

Among different mixes of Pongamia pinnata biodiesel tried in VCR motor with turbo charger arrangement. The B20 has the least fumes attributes and better execution qualities.

Hence $20 \%$ PME oil and $80 \%$ of diesel blend at standard temperature of $27^{\circ} \mathrm{C}$ and standard compression ratio 18:1 gives slightly better performance and reduced emission when compared to other diesel blends.

\section{REFERENCE}

1. S. Sendilvelan, K. Bhaskar, Rasayan Journal of Chemistry, 9 (4), 692(2016)

2. S. Sendilvelan, K. Bhaskar, Rasayan Journal of Chemistry, 10 (1), 111(2017)

3. S. Sendilvelan, K. Rajan, Rasayan Journal of Chemistry, 10 (1), 190(2017) 12

4. S. Sendilvelan, K. Bhaskar, Rasayan Journal of Chemistry, 10 (3), 844(2017)

5. Horng-WenWu, Zhan-YiWu, "Using Taguchi method on combustion performance of a diesel engine with diesel/biodiesel blend and port-inducting H2" Applied Energy, Volume 104, April 2013, Pages 362-370.

6. P.Deivajothi, V.Manieniyan and S. Sivaprakasam, "Experimental Investigation on the Effect of Thermal Cracked Carbon Filtered Fatty Acid Biodiesel on Engine Performance and Exhaust Emission" International Journal of Engineering Trends and Technology (IJETT) Volume 38 Number 7- August 2016.

7. M. Prabhahar, and K. Rajan, Performance and combustion characteristics of a diesel engine with titanium oxide coated piston using Pongamia methyl ester, Journal of Mechanical Science and Technology 27 (5) (2013) 1519 1526

8. M. Prabhahar, S. Sendilvelan, S. Prakash and M. Saravanakumar, Investigation Of Pine Oil Methyl Ester Blends With Diesel On A Compression Ignition Engine To Control Oxides Of Nitrogen And Soot Particles, Rasayan j.Chem. Vol. 10 | No. 4 |1075-1079| October December | 2017 ISSN: 0974-1496

9. Paula Berman, Shahar Nizri, Zeev Wiesman, (2009)," Castor oil biodiesel and its blends as alternative fuel", 86 (2009) 2476-2486

10. V Naresh and S Prabhakar, "Performance and Emission Characteristics of Algae Oil on VCR Diesel Engine" Journal of Chemical and Pharmaceutical Research, 2018, 10(4): 44-55, ISSN : 0975-7384.

11. M.K.-K. Figueiredo, G.A. Romeiro, L.A. d Avila, R.N. Damasceno, A.P. Franco (2011),'The isolation of pyrolysis oil from castor seeds via a Low Temperature Conversion (LTC) process and its use in a pyrolysis oil-diesel blend Fuel", 90 (2011) 2089-2097

12. Abdolsamad Zarringhalam Moghaddam, Erfan Salimipour, Ojtaba Saei Moghaddam and Nooshin Gholipour Zanjani (2011), "Improvement fuel properties and emission reduction by use of Diglyme-Diesel fuel blend on a heavy-duty diesel engine", International Conference on Environmental Engineering and Applications, Vol. 17, pp. 210-214.
13. Abhang B. and Hameedullah M. (2011), "Determination of optimum parameters for multi-performance characteristics in turning by using grey relational analysis", International Journal Adv Manuf Technology, pp.1-12.

\section{AUTHORS PROFILE}

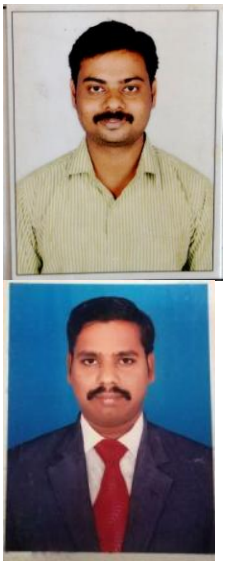

S.Prakash -Research Scholar

Department of Mechanical Engineering, Vinayaka Mission Research Foundation, Deemed to be University Prakash.mech94@gmail.com

Dr. M.Prabhahar - Professor

Department of Mechanical Engineering, Aarupadai Veedu Institute of Technology Vinayaka Mission Research Foundation, Deemed to be University mprabhahar@gmail.com 